\title{
선회유동을 이용한 펠릿연소기의 화염안정화 연구 A Study on The Flame Stability of Pellet Combustor Using Swirling Flow
}

\author{
이도형*† - 윤봉석** - 왕진위*** \\ Do-Hyung Lee*† , Bong-Seok Yun** and Zhen-Wei Wang***
}

(접수일 : 2014년 7월 31일, 수정일 : 2014년 8월 29일, 채택확정 : 2014년 9월 1일)

\begin{abstract}
The wood pellet, which is one of the woody biomass energy, has very high economic efficiency and combustion efficiency during their combustion. The existing pellet burner have many problems such as low combustion efficiency, flame stabilization, ash problem and ignition time etc. We developed cyclonic wood pellet burner aim to $20,000 \mathrm{kcal} / \mathrm{hr}$ boiler and measured temperature profiles and exhaust gases in order to investigate the flame stability and optimum combustion condition at any air flow conditions. As results, we confirmed the reappearance and the isotropy of the experimental results in the burner. At the first air flow inlet condition of excess air ratio $a=0.02$, second air flow $490 \ell / \mathrm{min}$ had the best combustion condition when pellet supplied 30g. This result means that we need much air supply only for the swirling of second air flow. So we tested various second air flux at first air excess air ratio $a=0.7$ condition. At this condition, we could find out that we don't need much second air and total air flux compared to the former condition. We will continuously test this work of air flow distribution, and swirl effect of first air flow, and ash elimination.
\end{abstract}

Key Words : Pellet Combustor, Flame Stability, Excess Air Ratio, Gas Analysis, Combustion Efficiency

\section{1. 서 론}

세계적으로 에너지 고갈에 대한 우려와 지구온 난화 등 환경문제가 절박한 상황이다. 우리나라는 에너지 소비량 세계 10 위권의 에너지 수입에 의 존하는 다소비국가이며 특히, 천연가스 수입은 일 본에 이어 세계 2 위의 수입국이다. 최근 우리나라 도 신재생에너지에 대한 관심이 높아, 다양한 분
야에 대한 연구개발 및 정부지원이 활발한 실정 이다.

우리나라의 신재생에너지 현황은 아직 태양광, 풍력, 연료전지 등은 약 $7 \%$ 이고, 수력이 약 $13 \%$, 폐기물이 약 $67 \%$, 그리고 바이오에너지가 약 $12 \%$ 를 차지한다. ${ }^{1)}$ 또한 바이오에너지 중에서도 바이 오디젤 등을 제외한 목질계 바이오에너지가 약 $43 \%$ 에 해당하며, 이들은 우드칩, 폐목재, 목재펠
*† 이도형(교신저자) : 부경대학교 기계공학과

E-mail : leedh@pknu.ac.kr, Tel : 051-629-6132

** 윤봉석 : 부경대학교 기계공학과

*** 왕진위 : 부경대학교 기계공학과

\footnotetext{
$* \dagger$ Do-Hyung Lee(corresponding author) : Department of Mechanical Engineering, Pukyong National University.

E-mail : leedh@pknu.ac.kr, Tel : 051-629-7710

** Bong-Seok Yun : Department of Mechanical Engineering, Pukyong National University.

*** Zhen-Wei Wang : Department of Mechanical Engineering, Pukyong National University.
} 
릿, 성형탄, 임산연료 등으로 구성되어 대부분 직 접연소에 의해 에너지화되고 있는 실정이다. ${ }^{2}$

목재펠릿은 톱밥을 압축 성형한 연료이며, 발열 량은 약 $4,500 \mathrm{kcal} / \mathrm{kg}$ 로 비교적 높은 편이며 경유 발열량 약 $9050 \mathrm{kcal} / \ell$ 의 절반 수준이지만, 현재 펠릿 $1 \mathrm{~kg}$ 의 가격은 약 300 원이고 발열량 대비 경 유 가격은 절반이어서 경제성이 월등히 앞선다. 또한 온실가스 배출이 경유 대비 $1 / 12$, 도시가스 대비 $1 / 10$ 수준으로 그 저감효과가 우수하다. ${ }^{3)}$

펠릿보일러는 목재펠릿을 연료로 열을 생산하 는 장치로써 세계적으로 개발 및 보급이 활성화 되어 있다. 국내에서도 농업용, 시설원예용 및 산 업용으로 널리 사용되고 있으며, 최근에는 열병합 발전용 및 스털링엔진의 연소기 등으로 개발되고 있다.

펠릿보일러의 핵심기술은 연소기술인데, 대부 분 독일 등 유럽국가가 핵심기술을 보유하고 있 으며, 국내 기술수준은 아직 선진국의 약 $41 \%$ 에 불과하다.) 정부에서는 '목재펠릿보일러 성능·구 조 및 설치기준’을 마련하여 기술수준을 강화하고 있으나 펠릿연소기는 아직 초기점화, 화염안정화, 회분 및 분진처리 그리고 역화 등 많은 해결과제 가 많다.

최근 국내에서도 펠릿보일러의 성능해석, 목재 펠릿의 연소해석, 그리고 연소실 내부의 연소현상 에 대한 다양한 연구가 진행되고 있다. 이들 중에 는 펠릿보일러의 성능에 관한 연구 ${ }^{4,5}$ 와 상용코드 를 이용한 연소실 해석기법 개발을 한 연구6,7) 등 이 있으며, 이들은 열효율 증가를 위해 공기량 제 어가 중요하다는 것을 확인하였다. 한편, 연소기 의 구조를 회전원판식으로 하고 역화방지장치를 부착한 개발연구 ${ }^{8,9}$ 도 있다. 그러나 이들 연구결과 를 상용화하기 위해서는 연소장치가 간단하면서 도 공기량 제어와 화염안정화가 우수한 연소기 개발이 필요하다.

본 연구는 이러한 기존 펠릿연소기의 문제점을 해결하기 위해 $20,000 \mathrm{kcal} / \mathrm{hr}$ 급 펠릿보일러를 기 준으로 한 사이클론식 연소기를 설계하여 그 첫 번째 단계로, 투입연료량에 대응하는 완전연소에 도달하는 시간과 화염안정화, 그리고 최적의 연소
조건을 찾는 것을 목표로 하였다. 따라서 연소기 중앙에서 유입되는 1 차 공기와 연소기 상류에서 선회기를 통하여 들어오는 2차 공기를 배분하여, 이때 연소실 내 화염의 재현성과 등방성을 확인 한 후, 공기량 배분에 대한 온도 및 각종 농도를 측정하였다. 이 기술은 펠릿연소뿐만 아니라 $\mathrm{RDF}$ 등 모든 고형연료의 연소에 널리 적용될 수 있는 기술이다.

\section{2. 실험장치 및 방법}

Fig. 1은 본 연구에서 개발한 펠릿연소기의 설 계도이며, 외경 $100 \mathrm{~mm}$, 높이 $300 \mathrm{~mm}$ 의 연소실 중 앙에 직경 $25 \mathrm{~mm}$ 의 1 차 공기 주입부 내에 점화봉 이 삽입되어 있고, 아래쪽을 통해 2차 공기가 선 회기를 통하여 연소실로 주입된다.
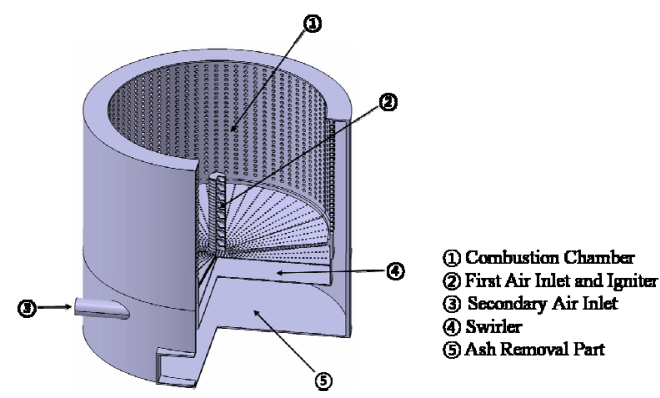

Fig. 1 Design of pellet combustor

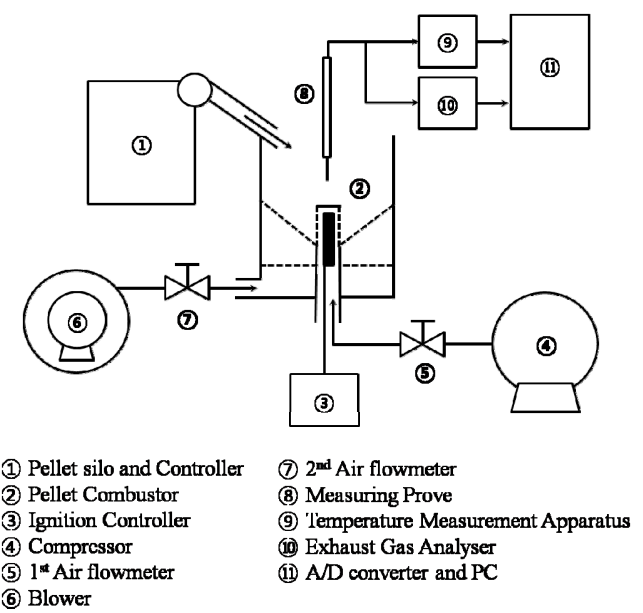

Fig. 2 Experimental apparatus 
Fig. 2에는 실험장치를 나타내었다. 실험장치는 전술한 연소실과 1,2 차 공기 주입부, 그리고 펠릿 공급장치와 각종 제어장치로 구성된다. 또한, 온 도 및 배기가스 농도 측정을 위한 측정장치 및 데 이터 처리장치를 설치하였다.

온도의 측정은 직경 $0.5 \mathrm{~mm}$ 의 $\mathrm{Pt} / \mathrm{Pt}-\mathrm{Rh} 13 \%$ 의 열전대를 삽입한 프로브를 연소기 내부에 넣어 측정하였다. 또한 각종 농도의 측정을 위해서는 배기가스 측정용 프로프를 연소기 내에 삽입하여 진공흡입한 가스를 측정하였으며, Horiba사의 배 기가스분석장치를 이용하여 분석하였다. 측정한 모든 데이터는 A/D converter를 이용하여 4개의 채널을 통해 20 초간 샘플링한 평균값을 사용하였 다. 한편, 온도 및 배기가스 농도 측정을 위하여 3 차원 이송장치를 사용하여 연소공간 내부의 반 경방향 및 축방향의 데이터를 효율적으로 얻고자 하였다.

실험조건으로는 연료펠릿 투입량 $15 \mathrm{~g}$ 및 $30 \mathrm{~g}$ 에 대해 1 차 공기량을 $2 \ell / \mathrm{min}$ 으로 고정하고 2차공기 량을 변화시킨 경우(Table 1)와, 1 차공기량을 $50 \ell$ $/ \min (a=0.7)$ 으로 고정하고 2 차 공기량을 변화시킨 경우(Table 2)로 나누어 실험을 진행하였다. 따라 서 Table 1의 실험조건으로는 각각의 연료투입량 에 대한 2 차 공기 주입량 변화에 의해 완전연소 시간과 화염안정화 및 최적 연소조건을 찾는 것 이 목적이며, Table 2 의 실험조건으로는 1 차 공기 량의 비중을 높게 하여 2 차 공기, 따라서 총 공기

Table 1 Experimental conditions(First air flux $2 \ell / \mathrm{min}$ )

\begin{tabular}{|c|c|}
\hline Fuel supply & 2st Air \\
\hline \multirow{4}{*}{$15 \mathrm{~g}$} & $140 \ell / \mathrm{min}$ \\
\cline { 2 - 2 } & $210 \ell / \mathrm{min}$ \\
\cline { 2 - 2 } & $280 \ell / \mathrm{min}$ \\
\cline { 2 - 2 } & $490 \ell / \mathrm{min}$ \\
\hline \multirow{4}{*}{$30 \mathrm{~g}$} & $140 \ell / \mathrm{min}$ \\
\cline { 2 - 2 } & $210 \ell / \mathrm{min}$ \\
\cline { 2 - 2 } & $280 \ell / \mathrm{min}$ \\
\cline { 2 - 2 } & $490 \ell / \mathrm{min}$ \\
\cline { 2 - 2 } & $560 \ell / \mathrm{min}$ \\
\hline \multirow{4}{*}{$30 \mathrm{~g}$} & $280 \ell / \mathrm{min}$ \\
\hline \multirow{4}{*}{} & $490 \ell / \mathrm{min}$ \\
\cline { 2 - 2 } & $560 \ell / \mathrm{min}$ \\
\hline
\end{tabular}

Table 2 Experimental conditions(First air excess air ratio $a=0.7$ )

\begin{tabular}{|c|c|}
\hline Fuel supply & 2st Air \\
\hline \multirow{4}{*}{$30 \mathrm{~g}$} & $50 \ell / \mathrm{min}$ \\
\cline { 2 - 2 } & $100 \ell / \mathrm{min}$ \\
\cline { 2 - 2 } & $150 \ell / \mathrm{min}$ \\
\cline { 2 - 2 } & $200 \ell / \mathrm{min}$ \\
\hline
\end{tabular}

량을 줄였을 때의 효율적인 연소조건을 찾고자 하였다.

\section{3. 결과 및 고찰}

\section{1 완전연소시간 및 소염기간 측정}

Fig. 3은 펠릿 연료 투입량이 각각 $15,30,60 \mathrm{~g}$ 인 경우에 완전연소시간과 소염시간을 타나내었 다. 여기서 완전연소시간이란 투입된 펠릿이 연소 하여 회분에 열이 남아, 새로이 연료를 투입하면 자력으로 화염을 이룰 수 있는 시간까지를 의미 하며, 소염시간이란 투입된 펠릿이 완전연소한 후 불이 꺼지고 회분이 남은 시점까지를 의미한다. 따라서 완전연소시간을 명확히 알면 주어진 조건 에서 단위시간당 연료투입 시점을 결정할 수 있 게 되어, 최종적으로 연소기의 안정적인 열부하를 알게 된다. 당연한 일이지만 연료량이 증가할수록 완전연소시간은 길어지고, 연소용 공기량이 많이 들어갈수록 짧아지는 경향이다. 위 그림에서 알 수 있듯이 연료투입량 $30 \mathrm{~g}$ 인 경우, 2 차 공기를 $280 \ell / \mathrm{min}$ 넣었을 때 완전연소에 걸리는 시간은 약 3 분이 소요됨을 의미한다.

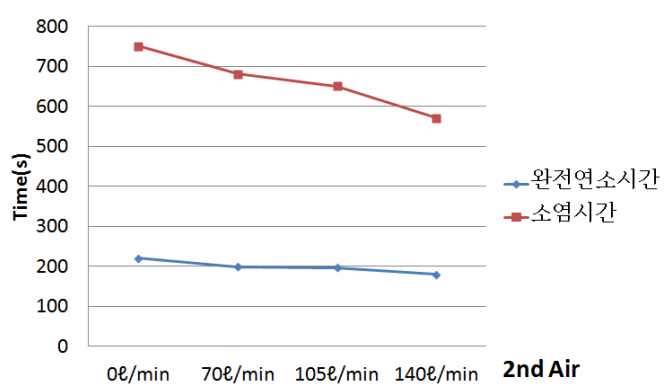

(a) Fuel $15 \mathrm{~g}$ at $1 \mathrm{st}$ air $2 \ell / \mathrm{min}$ 


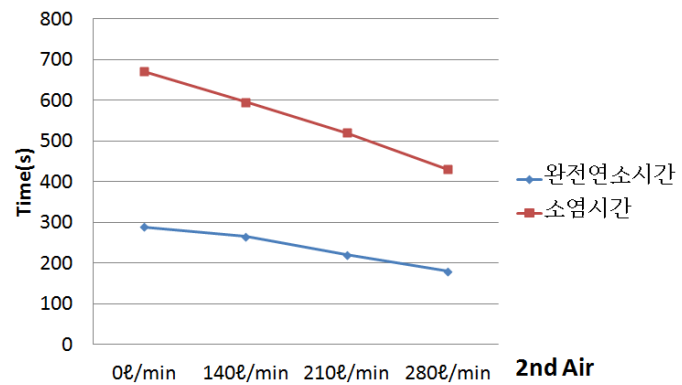

(b) Fuel $30 \mathrm{~g}$ at 1 st air $2 \ell / \mathrm{min}$

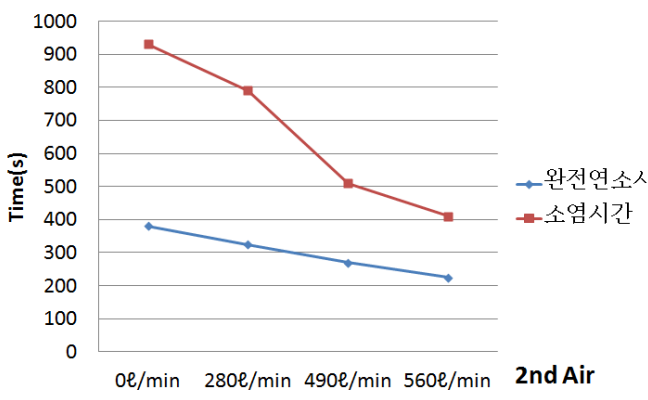

(c) Fuel $60 \mathrm{~g}$ at $1 \mathrm{st}$ air $2 \mathrm{\ell} / \mathrm{min}$

Fig. 3 Complete combustion time and quenching time

\section{2 연소온도의 측정과 등방성 확인}

연소실험은 Fig. 4에 나타낸 바와 같이, 펠릿을 1 차 투입 후 점화시키고, 점화 후 2 분 동안 연소 시키고 펠릿을 2차 투입한다. 또한 2분 연소시킨 후 다시 펠릿을 3 차 투입하여 이후 완전연소시켜 총 3 차례 연소시키는 동안의 온도 및 각종 화학종 농도의 시간평균을 측정하였다. 이는 이전의 실험 결과에서 확인한 것이며, 이 3차례의 펠릿 투입 후의 연소실 내의 온도분포가 거의 일치함을 보 여준다. 한편, 연소실 내의 온도는 최대 $800^{\circ} \mathrm{C}$ 정 도로 낮게 나타났는데, 이는 후술하는 바와 같이 1,2 차의 총 공기량이 많이 주입되기 때문이다.

또한 이 동안의 실험의 재현성과 연소기 반경 방향의 등방성을 확인하기 위하여, 연소기 축방향 $\mathrm{Z}=100 \mathrm{~mm}$ 에서 임의 반경 $\mathrm{R}(\mathrm{x})$ 및 그와 직각인 반 경 $\mathrm{R}(\mathrm{y})$ 방향의 각 위치에서의 온도를 측정한 결과 를 Fig. 5에 나타내었다. 점화시기와 펠릿 1 3차 투입시의 온도 증감이 명확히 구분되며, 온도도 비슷한 높이를 유지하는 점으로 보아 몇 번의 펠

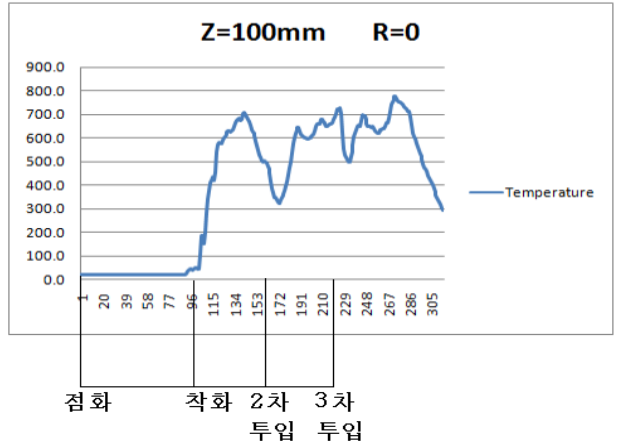

Fig. 4 Ignition and fuel supply

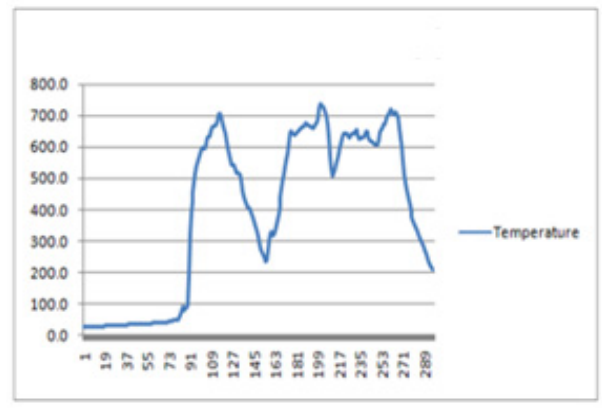

(a) $\mathrm{R}(\mathrm{x})=10 \mathrm{~mm}$

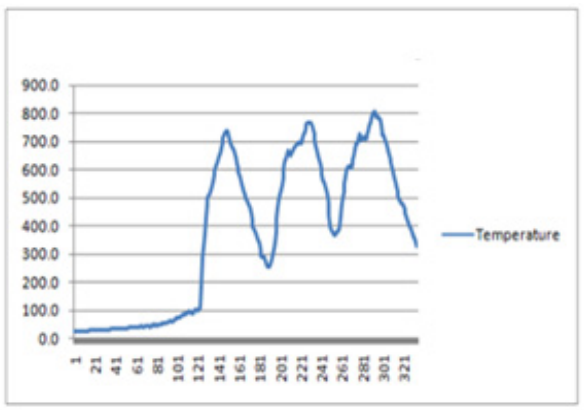

(b) $\mathrm{R}(\mathrm{y})=10 \mathrm{~mm}$

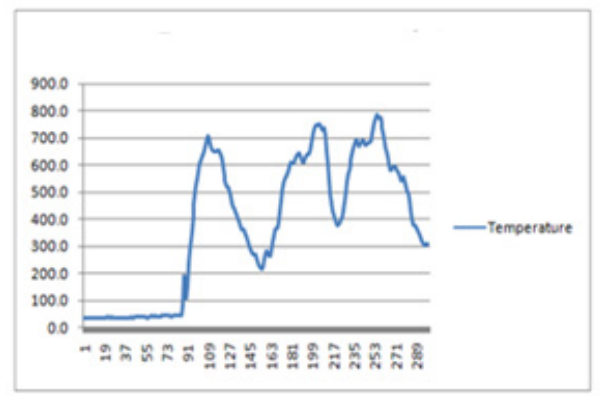

(c) $\mathrm{R}(\mathrm{x})=20 \mathrm{~m}$

Fig. 5 Temperature distributions at $\mathrm{Z}=100 \mathrm{~mm}$ (fuel $30 \mathrm{~g}, 1$ st air $2 \ell / \mathrm{min}, 2 \mathrm{nd}$ air $490 \ell / \mathrm{min}$ ) 
릿 투입이어도 지속적으로 연소가 이루어지고 있 음을 알 수 있다. 또한 $\mathrm{R}(\mathrm{x})$ 와 $\mathrm{R}(\mathrm{y})$ 의 온도분포가 거의 일정한 것으로 보아, 연소기 반경방향 어느 위치에서도 일정한 데이터를 얻을 수 있을 것으 로 판단된다.

\section{3 배기가스 분석}

Fig. 6 에는 Table 1 의 실험조건에서 펠릿 $30 \mathrm{~g}$ 주 입일 때의 $\mathrm{Z}=100 \mathrm{~mm}$ 위치에서 각종 배기가스를 분석한 결과를 나타내었다. 여기에 나타내지는 않 았으나, 실험에서 화염을 관찰하면 2차 공기 140 $\ell / \mathrm{min}$ 인 경우에는 2 차공기량이 부족하여 화염길 이가 길고 연소 또한 활발하지 못하였다. 그러나 이 조건을 제외하고는 대부분 연소는 잘 이루어 지고 있었다. 그럼에도 불구하고 그림 (a)에 보인 바와 같이 $\mathrm{CO}$ 의 양이 많이 나타났다. 이는 그림 (b)의 $\mathrm{HC}$ 농도에서도 알 수 있듯이 아직 완전연 소에는 이르지 못함을 알 수 있다. 이는 그림 (d) 의 $\mathrm{CO}_{2}$ 농도가 일반적인 연소에서 얻어지는 값보 다 적게 나타나는 데서도 알 수 있다.

이는 대부분의 연소가 선회기를 통하여 공급 되는 2 차 공기에 의해 지배되는데, 공기 유량에 대응하는 적정한 선회 효과가 연소에 영향을 끼 치는 것으로 생각된다. 따라서 2차 공기량 $490 \ell$ $/ \mathrm{min}$ 인 경우에 $\mathrm{CO}$ 와 $\mathrm{HC}$ 의 양이 상대적으로 줄 어들어, 본 장치에서는 이 부근의 공기 공급이 적합함을 알 수 있다. 한편, 그림(c)의 $\mathrm{NOx}$ 는 모 든 조건에서 기준치인 $150 \mathrm{ppm}$ 이내의 값으로 나 타났다.

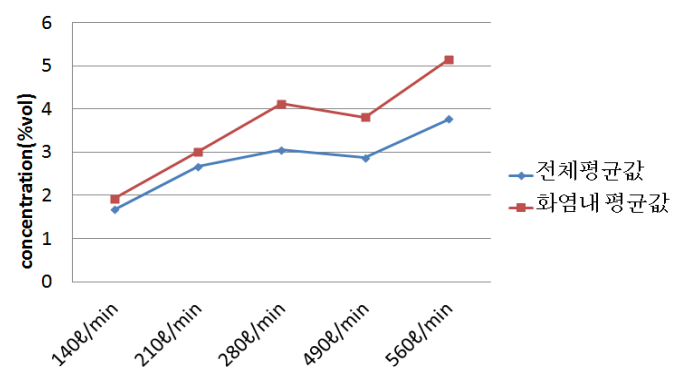

(a) $\mathrm{CO}$

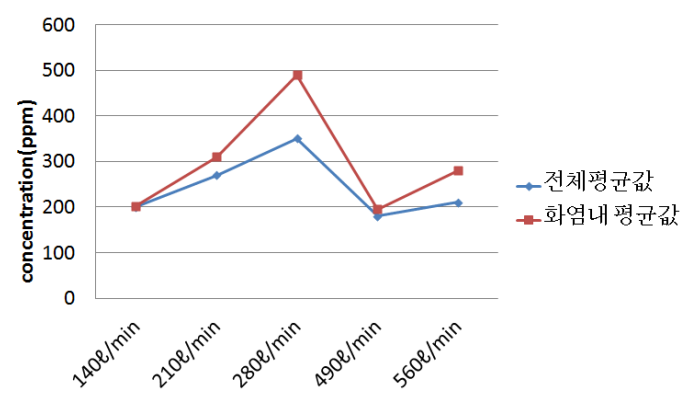

(b) $\mathrm{HC}$

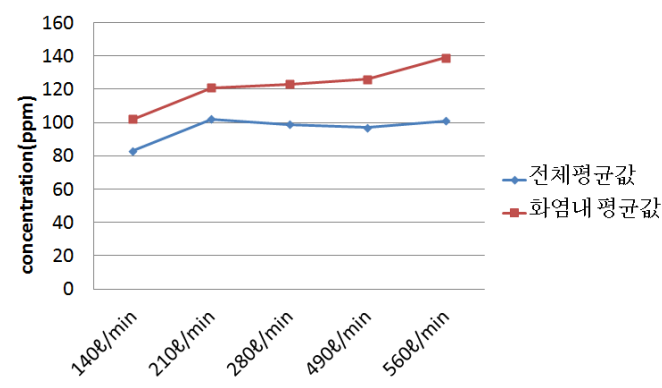

(c) $\mathrm{NO}_{\mathrm{x}}$

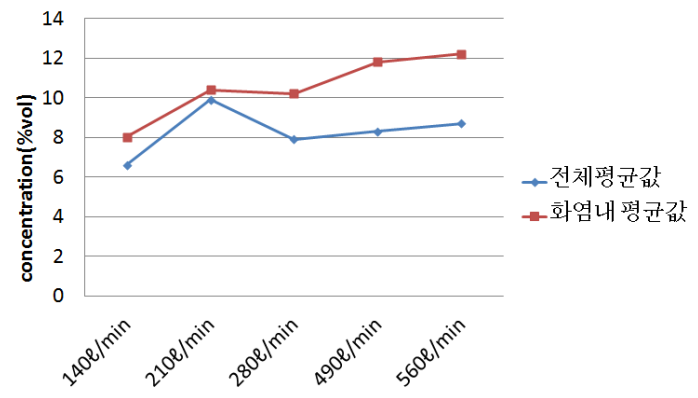

(d) $\mathrm{CO}_{2}$

Fig. 6 Distributions of exhaust gases(Fuel 30g, 1st air $2 \ell / \mathrm{min}, \mathrm{Z}=100 \mathrm{~mm}$ )

\section{4 공급공기량 배분에 대한 고찰}

위 실험에서는 1 차공기량을 고정하고 2 차 공기 를 선회기를 통하여 대량으로 주입하여 완전연소 에 도달하는 시간과 이때의 화염안정성, 그리고 선회에 의한 회분 처리 가능성을 살펴보고자 실 험하였다. 따라서 2 차공기의 과잉 주입으로 인해 연소온도는 낮고, 때때로 불완전연소를 유발하는 경우도 있다. 이에 이하의 실험에서는 Table 2 에 나타낸 실험조건과 같이, 1 차공기량을 $50 \ell / \mathrm{min}$ 로 늘리고 2 차공기량을 변화시킨 경우에 대하여 실 험하여, 총 공급공기량을 줄이면서 완전연소를 유 
도하는 방법을 모색하는 기초자료로 활용하고자 한다.

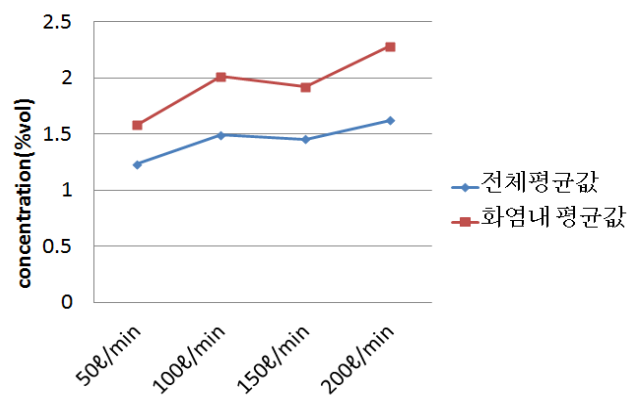

(a) $\mathrm{CO}$

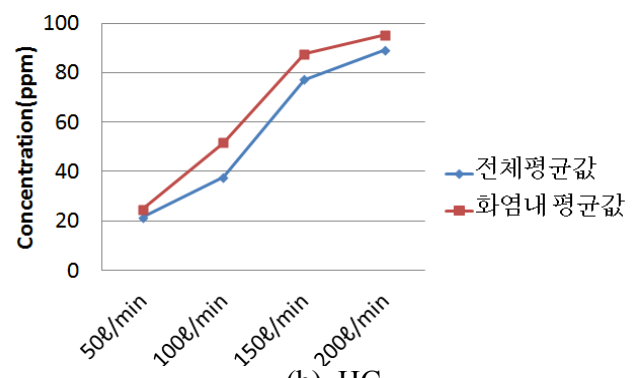

(b) $\mathrm{HC}$

Fig. 7 Distributions of Exhaust gas(Fuel 30g, 1st air $50 \ell / \mathrm{min}, \mathrm{Z}=100 \mathrm{~mm}$ )

Fig. 7는 위의 실험조건에서 연소기 높이방향 $\mathrm{Z}=100 \mathrm{~mm}$ 에서의 $\mathrm{CO}$ 및 $\mathrm{HC}$ 의 평균농도를 나타내 었다. 이전 실험의 최적 조건인 2차 공기 $490 \ell$ $/ \mathrm{min}$ 의 경우(Fig. 4-11)와 현재 실험의 2 차 공기 50 $\ell / \mathrm{min}$ 에 비교하면, $\mathrm{CO}$ 는 절반 이상, 특히 $\mathrm{HC}$ 는 약 $1 / 10$ 로 줄었음을 알 수 있다. 이는 현재의 실험 조건이 이전의 조건에 비하여 완전연소에 가까워 졌다는 것을 의미한다. 이에 관한 실험의 관찰에 의해서도 선회효과는 확연히 줄어들지만 불의 길 이가 이전과 비슷하며, 연소기 하부의 연소상황이 좋았음을 확인하였다. 따라서 2 차 공기의 선회효 과를 고려하지 않는 경우에는 1 차 공기의 양을 늘 리고 2 차 공기량을 줄이는 것이 결과적으로 총 공 급공기를 상당히 줄이게 되어, 효율적인 연소가 된다는 것을 알 수 있었다.

본 실험에서는 $30 \mathrm{~g}$ 의 펠릿은 2 차 공기의 최저
값인 $50 \ell / \mathrm{min}$ 의 조건에서 2 분 이내에 완전연소 하였으며 이때의 공기비는 1.4 정도가 되었다. 이 는 본 연구에서 개발한 연소기가 기존 연소기의 공기비 18 2.0에 비하여 훨씬 적은 공기비로 완전 연소가 가능함을 보여준다.

\section{4. 결 론}

본 연구는 다양한 고형연료 중에서 펠릿의 효 율적인 연소를 위한 연소기를 개발하는 것이 목 적이다. $20,000 \mathrm{kcal} / \mathrm{hr}$ 급 펠릿보일러를 기준으로 사이클론식 연소기를 설계하고, 연료투입, 1,2 차 공기 공급장치, 점화장치 등을 설계에 반영하여 실험한 결과, 적절한 동작이 됨을 확인하였으며, 다음과 같은 결론을 얻었다.

1. 펠릿이 주어진 공급공기 조건에서 얼마동안 연소하는가는 펠릿을 공급장치를 통하여 간헐적 으로 공급하는 시기를 결정하는 인자이다. 본 실 험조건에서는 2 분마다 투입하여 완전연소가 됨을 확인하고 실험을 진행하였다.

2. 개발한 연소기가 임의 반경방향으로 등방성 을 갖추었는지, 또한 펠릿이 실험도중 수시로 투 입되므로 실험의 재현성이 있는지를 온도분포를 통하여 확인한 결과, 신뢰할만한 데이터를 얻을 수 있었다.

3. 1 차 공기 $2 \ell / \mathrm{min}$ 인 경우의 실험조건에서 배 기가스 농도를 측정한 결과, $15 \mathrm{~g}$ 의 연료를 주입한 경우 2 차 공기 $210 \ell / \mathrm{min}, 30 \mathrm{~g}$ 인 경우에는 $490 \ell$ $/ \mathrm{min}$ 적정한 공기량으로 판단된다.

4. 1 차 공기 $2 \ell / \mathrm{min}$ 인 경우에 연소기 내의 온 도는 대부분 $800^{\circ} \mathrm{C}$ 정도로 낮게 나타났는데, 이는 전체 공기량이 많기 때문이다. 본 실험에서는 1 차 공기를 좀 더 주입하고 2차 공기를 상당히 줄인 상태, 예를 들어 공기비 $\mathrm{a}=1.4$ 인 경우에도 안정적 연소를 하고 있음을 확인하였다. 이는 일반적인 펠릿연소에 필요한 공기비 $\mathrm{a}=1.8 \sim 2.0$ 인 경우보다 훨씬 적은 공기량이다. 따라서 장차 1 차 공기의 주입 유동을 좋게 함으로써 더욱 효율적인 연소 가 가능하여, 추가적인 공기량 배분에 관한 실험 을 필요로 한다. 
추후 더욱 우수한 점화장치 개발, 공기량 배분 실험, 선회효과에 의한 회분 처리 등의 실험을 추 가하여 고효율의 고형연료 연소기를 개발할 예정 이다.

\section{후 기}

이 논문은 부경대학교 자율창의연구비(2013년 : C-D-21013-0408)에 의하여 연구되었음.

\section{Reference}

1. New \& Renewable Energy Center, 2007, "New \& Renewable Energy R\&D Strategy 2030[Woody Bioenergy]", pp. 27 34.

2. Korea Forest Service, 2009, "A Energy Counterplan of Wood Pellet(Report)".

3. Korea Forest Service, 2010, "A Research on the actual Condition of Wood Pellet Use and Stable Supply Plan(Report)".

4. B. S. Sim, J. J. Kim, K. S. Choi, S. B. Kang and J. S. Mun, 2010, "Combustion Characteristics of wood Pellet", Korean Society of Mechanical Engineering, Spring Proceeding, Vol. 28, No. 11, pp. 3624-3629.

5. J. J. Kim, G. S. Choi, S. B. Gang, J. S. Moon and H. Y. Oh, 2012, "Performance Characteristics of Wood Pellet Combustion facillities 200,000kcal/h-Class", Korean Society of Mechanical Engineering, Spring Proceeding, Vol. 30, No. 5, pp.276-278.

6. J. Ahn and J. H. Jang, 2011, "Combustion and Heat Transfer Characteristics inside the Combustion Chamber of Wood Pellet Boiler", The Society of Air-conditioning and Refrigerating Engineers of Korea, Winter Annual Meeting, Vol. 31, No. 11, pp. 363-366.

7. J. Ahn and J. H. Jang, 2011, "Numerical Simulation of Combustion Process of Wood Pellet", The Korean Society of Combustion, Fall
Annual Meeting, pp. 1-4.

8. C. H. Chung and M. C. Park, 2012, "Development of a High efficiency Wood Pellet Boiler with Improved Safety", The Korean Reliability Society, Vol. 12, No. 1, pp. 35-46.

9. C. H. Chung, M. C. Park and S. Y. Lee, 2013, "Development of Industrial Wood Pellet Boiler with High Safety", The Korean Reliability Society, Vol. 13, No. 1, pp. 31-44. 